\title{
Evaluation Research on Military Logistics Distribution Center Based on SVM
}

\author{
Fan Yang ${ }^{1, \text { a }}$, Zhanbiao Zhao ${ }^{1, \mathrm{~b}}$, Tianyuan Jiang ${ }^{2, \text { c }}$, Yucai Dong ${ }^{2, \mathrm{~d}}$ \\ ${ }^{1}$ Scientific Research Department, Academy of Armored Forces Engineering, Beijing, 100072, China \\ ${ }^{2}$ Foundation Department, Academy of Armored Force Engineering, Beijing 100072, China
}

\begin{abstract}
It is of vital importance to evaluate scientifically and accurately the ability of military logistics distribution center for promoting distribution efficiency and satisfying war requirements. Faced with the problem of low accuracy in evaluating the ability of current military logistics distribution center, this paper established an evaluation model with support vector regression, in which it shows great fitting efficiency with average relative error of $1.7536 \%$ after training the samples. Support vector machine promotes generalization ability through structural risk minimization, thus solving such practical problems as small sample data, non-lineal, high dimensions and local minima, which plays a significant role in evaluating the ability of military logistics distribution center.
\end{abstract}

Keywords-support vector machines (SVM); military logistics; distribution center.

\section{INTRODUCTION}

As the core hinge of military logistics system, military logistics distribution center has advanced modern hardware conditions and forms a comprehensive information network nodes, so that it can realize the networked and informatization in the logistics field. Therefore, evaluating the ability of military logistics distribution center scientifically and accurately is crucial to enhance the ability of military support and overall strength of our army. Given the importance of the military logistics distribution center, at present, many experts, scholars do many studies on the military logistics distribution center. According to military logistics distribution center operating characteristics, Feng Yun [1] analyzed the basic components of military logistics and distribution center processes, applied Flexsim software to simulate the distribution center. Yang Chun-zhou [2] used discrete binary particle swarm optimization (PSO) to solve the problem of distribution center selection and built the optimal model of the site selection about military logistics distribution center. Wang Hai-lan [3] proposed that the military logistics distribution center should be established as a storage and supply system based on MRP thought, set up a powerful MIS in order to optimize and improve the military logistics system. Mo Hai-ling [4] put forward an evaluation method of making use of the BP neural networks from the view of implementing the function of the military logistics distribution center. The eventually results by BP neural networks is consistent with the experience of experts and preferences, but the training samples in the article are not enough, which made results, to some degree, lack of reliability.

\section{BASIC PRINCIPLES OF V-SVR}

Compared with statistical theory, statistical learning theory (SLT) [5], brought by Vapnik, focuses on the machine learning of small sample size and can tradeoff between the complexity of models and generalization performance, and Support vector machines (SVM) is a kind of new classification and regression tool developed on SLT. Support Vector Regression mainly include $\varepsilon$-SVR, proposed by Vapnik [6] and $\mathrm{v}$-SVR, proposed by Sch lkopf [7]. $\varepsilon$-SVR can control accuracy the method hoping to arrive by making sure $\varepsilon$ in advance, and $v$-SVR can minimize $\varepsilon$ to insure the method has highest precision. SVR puts the practical problems to a high-dimensional feature space by non-linear transformation, and structures linear discriminant function in the high-dimensional feature space to realize the non-linear discriminant function in the original feature space. The algorithm complexity of this method is irrelevant to the dimension of samples, thus SVR is widely used [8-10].

$$
\begin{array}{llr}
\text { Suppose there is a training } & \text { set } \\
T=\left\{\left(x_{1}, y_{2}\right), \cdots\left(x_{l}, y_{l}\right)\right\} \in(X \times Y)^{l}, & \text { in } & \text { which } \\
x_{i} \in X=R^{n}, y_{i} \in Y=R, i=1,2, \cdots, l & \text {. } & \text { Adapt }
\end{array}
$$
non-linear mapping function $\phi(x)$ to map the input vector $X$ to feature space, then take linear regression analysis and build a regression function in high-dimensional feature space.

$$
f(x)=\omega^{T} \cdot \phi(x)+b .
$$

in which $\omega$ and $b$ represent weight vector and bias respectively. Introduce a slack variable $\xi^{(*)}=\left(\xi_{1}, \xi_{1}^{*}, \cdots, \xi_{l}, \xi_{l}^{*}\right)^{T}$ and penalty parameter $C$, build a quadratic programming original problem:

$$
\begin{gathered}
\min _{\omega \in R^{n}, \xi^{(*)} \in R^{2 l}, b \in R} \frac{1}{2}\|\omega\|^{2}+C \cdot\left(v \varepsilon+\frac{1}{l} \sum_{i=1}^{l}\left(\xi_{i}+\xi_{i}^{*}\right)\right) \\
\text { s.t. } \quad\left(\omega^{T} x_{i}+b\right)-y_{i} \leq \varepsilon+\xi_{i}, \quad i=1,2, \cdots, l \\
y_{i}-\left(\omega^{T} x_{i}+b\right) \leq \varepsilon+\xi_{i}^{*}, \quad i=1,2, \cdots, l \\
\varepsilon, \xi_{i}, \xi_{i}^{*} \geq 0, \quad i=1,2, \cdots, l
\end{gathered}
$$

The dual problem of function (2) is: 


$$
\begin{gathered}
\min _{\alpha^{(*)} \in R^{2 l}} \frac{1}{2} \sum_{i, j=1}^{l}\left(\alpha_{i}^{*}-\alpha_{i}\right)\left(\alpha_{j}^{*}-\alpha_{j}\right) K\left(x_{i}, x_{j}\right)-y_{i} \sum_{i=1}^{l}\left(\alpha_{i}^{*}-\alpha_{i}\right) \\
\text { s.t. } \quad \sum_{i=1}^{l}\left(\alpha_{i}^{*}-\alpha_{i}\right)=0 \\
0 \leq \alpha_{i}^{*}, \alpha_{i} \leq \frac{C}{l}, i=1,2, \cdots, l \\
\sum_{i=1}^{l}\left(\alpha_{i}^{*}-\alpha_{i}\right) \leq C \cdot v .
\end{gathered}
$$

Both $\alpha, \alpha^{*}$ are lagrangian multipliers, while $K\left(x_{i}, x_{j}\right)$ is a symmetric function which satisfies the conditions of Mercer. The commonly used kernel functions include Polynomial、RBF、Sigmoid kernel function and so on.

Algorithmic procedures of the $v$-SVR method:

$$
\text { Suppose there is a training }
$$
set $T=\left\{\left(x_{1}, y_{2}\right), \cdots\left(x_{l}, y_{l}\right)\right\} \in(X \times Y)^{l}$, in which $x_{i} \in X=R^{n}, y_{i} \in Y=R, i=1,2, \cdots, l$.

Select proper positive numbers $v, C$ and kernel function $K\left(x, x^{\prime}\right)$

Build and solve the optimization problem (3), get optimal solution $\bar{\alpha}=\left(\bar{\alpha}_{1}, \bar{\alpha}_{1}^{*}, \cdots, \bar{\alpha}_{l}, \bar{\alpha}_{l}^{*}\right)^{T}$

Build the decision function

$$
f(x)=\sum_{i=1}^{l}\left(\bar{\alpha}_{i}^{*}-\bar{\alpha}_{i}\right) K\left(x_{i}, x\right)+\bar{b}
$$

Select $\bar{\alpha}_{j}$ and $\bar{\alpha}_{k}^{*}$ in the open interval $\left(0, \frac{C}{l}\right)$. Let

$\bar{b}=\frac{1}{2}\left[y_{i}+y_{k}-\left(\sum_{i=1}^{l}\left(\bar{\alpha}_{i}^{*}-\bar{\alpha}_{i}\right) K\left(x_{i}, x_{j}\right)+\sum_{i=1}^{l}\left(\bar{\alpha}_{i}^{*}-\bar{\alpha}_{i}\right) K\left(x_{i}, x_{k}\right)\right.\right.$

\section{EVAluation OF Military Logistics DISTRIBUTION CENTER}

\section{A. Influencing factors of military logistics distribution} center evaluation

Literature [4] points out that in theory, a military logistics distribution center shall have the following functions: transportation, storage, loading and unloading, handling, circulation, processing and information handling. Then you can get 10 pairs of empirical data samples of military logistics distribution center on the basis of the empirical evaluation over the center by experts, as shown in Table 1. As for the function of transportation, the center shall be able to distribute the military materials to the army or its units directly. As for the function of storage, the center shall be able to provide continuous quality service to the army or its units the material they need through its storehouse. As the function of loading and uploading and handling, the center shall be able to conduct rapid handling operations with its specialized machinery to load, upload, hoist, transport, sort and stack military materials. As for the function of circulation and processing, the center shall be able to simply process military materials. As for the function of information processing, the center shall be able to continuously collect and monitor the real-time information of the military materials at different logistic chains and that the army and its units need to provide accurate and reliable service.

TABLE I. MAIN FACTOR INDICES AFFECTING THE ABILITY OF MILITARY LOGISTIC DISTRIBUTION CENTER

\begin{tabular}{|l|l|l|l|l|l|l|}
\hline $\begin{array}{c}\text { Sample } \\
\text { No }\end{array}$ & Transport & Storage & $\begin{array}{c}\text { loading } \\
\text { and } \\
\text { unloading } \\
\text { handing }\end{array}$ & $\begin{array}{c}\text { Circulation } \\
\text { and } \\
\text { processing }\end{array}$ & $\begin{array}{c}\text { information } \\
\text { processing }\end{array}$ & $\begin{array}{c}\text { Total } \\
\text { scores }\end{array}$ \\
\hline 1 & 0.73 & 0.91 & 0.8 & 0.85 & 0.75 & 0.81 \\
\hline 2 & 0.62 & 0.67 & 0.91 & 0.81 & 0.93 & 0.79 \\
\hline 3 & 0.85 & 0.73 & 0.84 & 0.95 & 0.82 & 0.82 \\
\hline 4 & 0.85 & 0.47 & 0.87 & 0.76 & 0.58 & 0.61 \\
\hline 5 & 0.83 & 0.84 & 0.8 & 0.92 & 0.94 & 0.89 \\
\hline 6 & 0.87 & 0.89 & 0.54 & 0.48 & 0.65 & 0.53 \\
\hline 7 & 0.84 & 0.95 & 0.72 & 0.91 & 0.81 & 0.86 \\
\hline 8 & 0.64 & 0.56 & 0.87 & 0.34 & 0.82 & 0.67 \\
\hline 9 & 0.85 & 0.73 & 0.67 & 0.93 & 0.74 & 0.77 \\
\hline 10 & 0.9 & 0.86 & 0.75 & 0.81 & 0.42 & 0.65 \\
\hline
\end{tabular}

\section{B. Establishing SVR models}

Take the functions of transportation, storage, loading and unloading, handling, circulation, processing and information handling as the input parameters and the total score as output parameters. Take radial basis function (RBF) as the adopted kennel function, then you get

$$
K\left(x, x^{\prime}\right)=\exp \left(-\gamma\left\|x-x^{\prime}\right\|^{2}\right)
$$

in which $\gamma=0.5$, penalty coefficient $C=1$, $v=0.5, \varepsilon=0.001$, thus establishing v-SVR model which trains the samples in 1-9 of Table I.

Table II shows what is contrasted between the actual values of the military logistics distribution center and the fitting values. It can be found that the fitting value of SVR is so small that all of them are smaller than $10^{-3}$, which means very good fitting effects. 
TABLE II. ACTUAL VALUES OF THE MILITARY LOGISTICS DISTRIBUTION CENTER AND FITTING VALUES OF SVR

\begin{tabular}{|c|c|c|c|c|}
\hline $\begin{array}{l}\text { Sample } \\
\text { No. }\end{array}$ & $\begin{array}{l}\text { Observed } \\
\text { value }\end{array}$ & $\begin{array}{l}\text { Fitting } \\
\text { value }\end{array}$ & $\begin{array}{l}\text { Fitting } \\
\text { error }\end{array}$ & Relative error \\
\hline 1 & 0.81 & 0.8100344 & $-3.44 \mathrm{E}-05$ & -0.00424 \\
\hline 2 & 0.79 & 0.790068 & $-6.8 \mathrm{E}-05$ & -0.00861 \\
\hline 3 & 0.82 & 0.8200344 & $-3.44 \mathrm{E}-05$ & -0.00419 \\
\hline 4 & 0.61 & 0.610249 & -0.000249 & -0.04083 \\
\hline 5 & 0.89 & 0.8897858 & 0.0002142 & 0.024066 \\
\hline 6 & 0.53 & 0.5300933 & $-9.33 E-05$ & -0.0176 \\
\hline 7 & 0.86 & 0.8599062 & 9.379E-05 & 0.010905 \\
\hline 8 & 0.67 & 0.6700864 & $-8.64 \mathrm{E}-05$ & -0.01289 \\
\hline 9 & 0.77 & 0.7697345 & 0.0002655 & 0.034486 \\
\hline \multicolumn{4}{|c|}{ Average relative error } & 0.017536 \\
\hline
\end{tabular}

C. Evaluation over the ability of a military logistics distribution center

SVR model is used to evaluate the comprehensive ability of the 10th military logistics distribution center, thus getting the following evaluation results as shown in Table III.

TABLE III. EVALUATION OVER THE ABILITY OF A MILITARY LOGISTICS DISTRIBUTION CENTER

\begin{tabular}{llll}
\hline $\begin{array}{l}\text { Observed } \\
\text { value }\end{array}$ & $\begin{array}{l}\text { Predicted } \\
\text { value }\end{array}$ & Fitting error & Relative error \\
0.65 & 0.6893179 & 0.039318 & 6.048908 \\
\hline
\end{tabular}

\section{SUMMARY}

The model of evaluating the ability of military logistics distribution center has been established with support vector regression. After training the samples, it shows good fitting efficiency and is used to conduction inspective evaluation over the ability of a military logistics distribution center. Support vector machine promotes generalization ability through structural risk minimization, thus solving such practical problems as small sample data, non-lineal, high dimensions and local minima, which is necessary not only in theory but in practice.

\section{REFERENCES}

[1] FENG Yun, ZHAI Yue-wen, Modeling and Simulation of Operation Process in Military Logistics Distribution Center. Journal of Logistical Engineering University, pp. 61-65, 2010.

[2] YANG Chun-zhou, ZHAN Xi-chen, WANG Hui-jin, Establishment of Military Logistics Distribution Center Model. Computer Simulation, pp. 19-23, 2012.

[3] WANG Hai-lan, TAO Xin-liang, Research on the Conversion of Rear Depot into Military Logistics Distribution Center. Logistics Technology, pp. 146-147, 2009.

[4] MO Hai-ling, MA Xiao-ping, LI Fei, LI Zi-dong, Research on the Evaluation of Military Logistics Distribution Center Based on BP Neural Networks. Journal of Academy of Military Transportation, pp. 62-64, 2006.

[5] Vapnik V N, An overview of statistical learning theory. IEEE Trans. On Neural Network, 10 (5), pp. 988-999, 1999.

[6] Vapnik V N, The nature of statistical learning theory. New York: Springer Verlag, pp. 656-660, 1995.

[7] Sch lkopf B et al, New support vector Algorithms. Neural Computation, 12, pp. 1207-1245, 2000.

[8] hia-Nan Koa, Cheng-Ming Leeb, Energy, 49, pp. 413-422, 2013.

[9] Jianyi Liu, Yao Ma, Lixin Duan, Fangfang Wang, Yuehu Liu, Signal Processing, 94, pp. 576-582, 2014.

[10] XU Da-jie, HAO Zhi-shuang, LIU Huan- zhang, The evaluation model of fighting efficiency of amphibious tank weapon system. Fire Control \& Command Control, 2 (33), pp. 82-88, 2008. 